7. Reprod. Fert. (1971) 24, 291-294

\title{
A STUDY ON SPERM TAIL ELEMENTS IN MOUSE BLASTOCYSTS
}

\author{
H. D. MaREYNOLDS AND R. HADEK \\ Department of Anatomy, Stritch School of Medicine, Loyola University of Chicago, \\ 2160 South First Avenue, Maywood, Illinois 60153, U.S.A.
}

(Received 13th August 1970)

Numerous studies have been published on the ultrastructural aspects of mammalian fertilization (Szollosi \& Ris, 1961; Hadek, 1963, 1969; Austin, 1968; Barros \& Franklin, 1968), and several recent articles have described changes in the head of the mammalian spermatozoon following its incorporation into the egg (Szollosi, 1965, 1969; Bedford, 1968; Hadek, 1969; Presley, 1969). Little attention, however, has been paid to the fate of the sperm tail in the cleaving ovum. Although the axial filaments of the fertilizing mouse spermatozoon can still be observed within the zygote a few hours after copulation (Presley, 1969), swelling and breakdown of the paternal mitochondria occur before the first cleavage, and the sperm tail disintegrates soon thereafter (Szollosi, 1969). Sperm tails (assumed to be supernumerary) have nevertheless been observed within the perivitelline space of the mouse zygote up to $24 \mathrm{hr}$ after mating (Presley, 1969), as well as between blastomeres in rabbit morulae (Hadek, unpublished observations) and rabbit blastocysts (Hesseldahl, 1969). Supernumerary spermatozoa have also been observed in intercellular spaces and within the trophoblast cells of the rat blastocyst (Tachi \& Kraicer, 1967; Tachi, Tachi \& Lindner, 1970). However, sperm tail elements have not so far been observed within the cells of pre-implantation mouse blastocysts. Recently, sperm tail elements were observed in the intercellular spaces and within the trophoblast cells of some mouse blastocysts which were cultivated in vitro from the morula stage of pre-implantation development in this laboratory. This communication is thought to provide the first description of the ultrastructure of sperm tail elements in the mouse blastocyst.

Embryos were removed from superovulated Swiss female mice at the late morula stage and were cultured for $26 \mathrm{hr}$ in vitro according to the method of Brinster (1963). The resulting blastocysts were fixed for $1 \mathrm{hr}$ in chilled $3.15 \%$ phosphate-buffered glutaraldehyde at pH 7.4 (Sabatini, Bensch \& Barrnett, 1963), rinsed for $3 \mathrm{hr}$ in cold phosphate buffer, and post-fixed for $30 \mathrm{~min}$ in $1 \%$ $\mathrm{OsO}_{4}$ at $\mathrm{pH} 7.4$ (Millonig, 1961). Following rapid dehydration in ethanol, the specimens were embedded in Epon 812 (Luft, 1961). Thin sections were cut on a Porter-Blum MT-1 ultrathin sectioning microtome, contrast was enhanced with uranyl acetate (Watson, 1958) followed by lead citrate (Reynolds, 1963), and the specimens were examined with an RGA EMU-3F-2 electron microscope. 
Electron microscopy revealed the presence of sperm tails within trophoblast cells of normal appearance in approximately one-sixth of the blastocysts examined. The sperm tails appeared to be surrounded by limiting membranes (Pl. 1, Figs. 1 to 4) and electron-dense, lysosome-like structures were often located in the vicinity of the inclusions (Pl. 1, Figs. 1, 4). In one blastocyst, an amorphous, lysosome-like body had apparently fused with the mid-piece of a sperm tail remnant to form an autolysosome (Pl. 1, Fig. 1). Slender mitochondria with few cristae often surrounded the mid-pieces of the sperm tails (P1. 1, Figs. 1, 4). Goarse, electron-dense external fibres of the sperm tails were usually present (Pl. 1, Figs. 1 to 4 ) but tubules of the central axial filament complex were not observed. Fortuitous sections demonstrated that some sperm tails were not completely engulfed because portions of the structures could be observed both within the cell as well as in the intercellular spaces (Pl. 1, Fig. 5).

In the mouse (Presley, 1969) and rat (Szollosi, 1965, 1969), the tail of the fertilizing spermatozoon usually disintegrates shortly after fertilization. Other features making the present observations unusual were: (1) the presence of apparently intact mitochondria in some sperm tails, and (2) the presence of limiting membranes which surrounded the tails of the incorporated spermatozoa. With regard to the former, Szollosi (1969) has shown that mitochondria associated with the fertilizing spermatozoon degenerate before the two-cell stage. Nevertheless, in addition to the present observations in the mouse blastocyst, sperm tail mid-pieces with intact mitochondria have also been observed in cells of the pre-implantation blastocyst of the rat (Tachi \& Kraicer, 1967). It is not known, however, whether mitochondria of paternal origin are functional after they have been incorporated into cells of cleaving embryos.

The limiting membranes are unusual since ultrastructural studies have demonstrated that the plasma membranes of both gametes fuse with one another

\section{EXPLANATION OF PLATE 1}

FIG. 1. A near cross section through the mid-piece of a sperm tail located within a trophoblast cell of a mouse blastocyst. Notice the limiting membrane (thick arrow) which surrounds the inclusion. The thin arrow points to a crista of a sperm-derived mitochondrion. Note the lysosome-like structure $(\mathrm{L})$ which has coalesced with the membrane surrounding the sperm tail. G, Golgi complex; $M$, mitochrondrion; $N$, nucleus of trophoblast cell; $R$, ribosomes. $\times 16,550$.

FIG. 2. An oblique section through the neck of the same sperm-derived inclusion which was observed in Fig. 1. The sperm tail is surrounded by a limiting membrane. The arrow denotes the connecting piece of the sperm tail. G, Golgi complex; M, mitochondrion; $\mathrm{N}$, nucleus of trophoblast cell. $\times 17,300$.

FIG. 3. A slightly oblique section through the neck region of a sperm tail located in a trophoblast cell of a pre-implantation mouse blastocyst. The arrow points to the limiting membrane which surrounds the sperm-derived inclusion. $M$, mitochondrion; $R$, ribosomes. $\times 19,700$.

FIG. 4. A section through the mid-piece of a sperm tail in a trophoblast cell of a preimplantation mouse blastocyst. Note the mitochondrial sheath which encloses the coarse external fibres. L, lysosome-like structure; R, ribosomes; $Z$, zona pellucida. $\times 15,750$.

FIG. 5. A section through an inner mass cell (IMC) and trophoblast cell (T) of a preimplantation mouse blastocyst. The section passes through a spermatozoon at three different levels. The mid-piece (observed previously in Fig. 4) has been incorporated into the trophoblast cell (single arrow, left side of micrograph) while portions of the mainpiece remain without the cell (two arrows, right side of micrograph). Z, zona pellucida. $\times 5900$. 

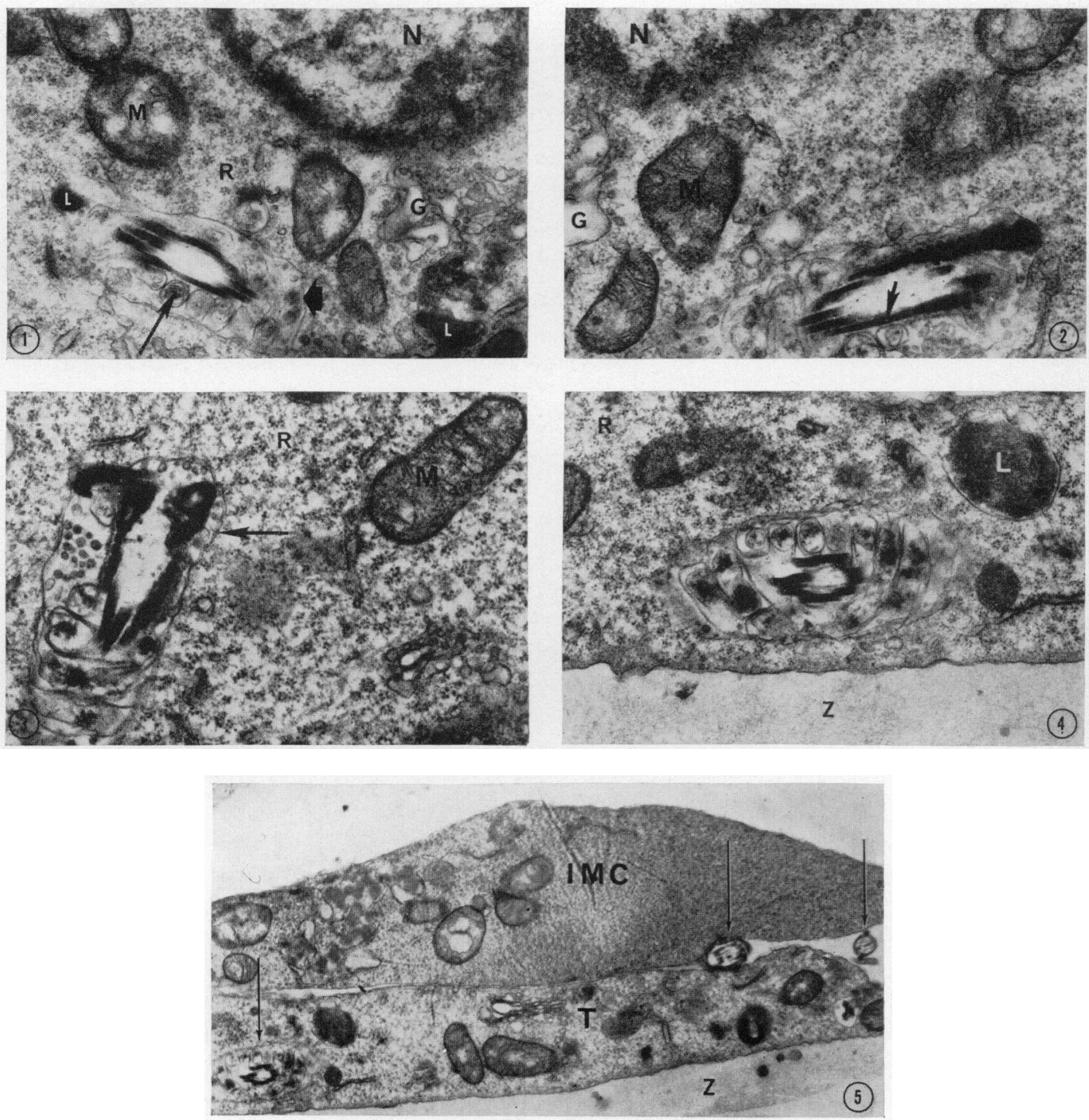

(Facing p. 292) 
at the time of sperm penetration into the egg (Colwin \& Colwin, 1961; Colwin \& Colwin, 1967; Barros \& Franklin, 1968), and electron microscopy has further demonstrated that the tail of the fertilizing spermatozoon does not manifest a cytolemma after it has been incorporated into the ovum (Bedford, 1968; Hadek, 1969; Presley, 1969; Szollosi, 1969).

In view of the above discussion, it is doubtful if the structures observed in this study were remnants of fertilizing spermatozoa. Instead, it is assumed that they were remnants of supernumerary spermatozoa which became incorporated into the cleaving embryos sometime after fertilization. Thus, the occurrence of supernumerary spermatozoa within cells of the mammalian blastocyst is not unique to the rat and the phenomenon may be of a more general nature than previously assumed. Phagocytosis may be the physiological mechanism by which supernumerary spermatozoa, located within the perivitelline space of the cleaving embryos, are destroyed.

This investigation was supported by Public Health Service Research Grant HD 00552-08 from the National Institute of Child Health and Human Development and in part by the institutional GRSG grant.

\section{REFERENCES}

Austin, G. R. (1968) Ultrastructure of fertilization, p. 44. Holt, Rinehart \& Winston, New York.

Barros, C. \& Franklin, L. E. (1968) Behavior of the gamete membranes during sperm entry into the mammalian egg. 7. Cell Biol. 37, C13.

BEDFORD, J. M. (1968) Ultrastructural changes in the sperm head during fertilization in the rabbit. Am. 7. Anat. 123, 329.

Brinster, R. L. (1963) A method for in vitro cultivation of mouse ova from two-cell to blastocyst. Expl Cell Res. 32, 205.

Corwin, A. L. \& Colwrs, L. H. (1961) Changes in the spermatozoon during fertilization in Hydroides hexagonus (Annelida). II. Incorporation with the egg. 7. biophys. biochem. Cytol. 10, 255.

Colwin, L. H. \& Colwin, A. L. (1967) Membrane fusion in relation to sperm-egg association. In: Fertilization, Vol. I, p. 295. Eds. C. B. Metz and A. Monroy. Academic Press, New York.

HADEK, R. (1963) Submicroscopic changes in the penetrating spermatozoon of the rabbit. 7 . Ultrastruct. Res. 8, 161 .

Hadek, R. (1969) Mammalian fertilization, an atlas of ultrastructure, Academic Press, New York.

Hesseldahl, H. (1969) Ultrastructure of rabbit ovum. Abstract presented at the Second Annual Meeting of the Society for the Study of Reproduction, September 8-10, 1969, at the University of California, Davis.

LuFT, J. H. (1961) Improvements in epoxy resin embedding methods. 7. biophys. biochem. Cytol. $9,409$.

Mullonig, G. (196I) Advantages of a phosphate buffer for $\mathrm{OsO}_{4}$ solutions in fixation. 7. appl. Physiol. 32, 1637.

Presley, R. (1969) Some electron-microscope observations on the fate of the sperm tail in rat and mouse ova. F. Anat. 104, 584 .

Reynolds, E. S. (1963) The use of lead citrate at high $\mathrm{pH}$ as an electron-opaque stain in electron microscopy. 7. Cell Biol. 17, 208.

Sabatini, D. D., Bensch, K. G. \& Barrnett, R. J. (1963) Cytochemistry and electron microscopy. The preservation of cellular ultrastructure and enzymatic activity by aldehyde fixation. $\mathcal{7}$. Cell Biol. 17, 19.

Szollosi, D. (1965) The fate of sperm middle-piece mitochondria in the rat egg. F. exp. Zool. 159, 367.

Szollosi, D. (1969) Degeneration of sperm mitochondrial complement in eggs. Abstract presented at the Second Annual Meeting of the Society for the Study of Reproduction, September 8-10, 1969, at the University of California, Davis.

Szollosi, D. \& Ris, H. (1961) Observations on sperm penetration in the rat. F. biophys. biochem. Cytol. $10,275$. 
TAchI, S. \& Kraicer, P. F. (1967) Studies on the mechanism of nidation. XXVII. Sperm-derived inclusions in the rat blastocyst. F. Reprod. Fert. 14, 401.

TACHI, S., TACH, G. \& LiNDNER, H. R. (1970) Ultrastructural features of blastocyst attachment and trophoblastic invasion in the rat. $\mathcal{F}$. Reprod. Fert. 21, 37.

Watson, M. L. (1958) Staining of tissue sections for electron microscopy with heavy metals. F. biophys. biochem. Cytol. 4, 475. 